\title{
The Distributional Survey Experiment
}

\section{Introducing a new method for the assessment of attitudes towards distributive justice}

\author{
Sandra Gilgen, University of Bern \\ sandra.gilgen@edu.unibe.ch
}

April 3, 2020

\begin{abstract}
What is a just allocation of goods for whom, when and why? Given that the answer to these questions involve need, merit and equality considerations and call for a multidimensional approach that takes individual, contextual and situational factors into account, we are in need of efficient methods designed to help tackle the complexity. The main aim of this contribution is to introduce the distributional survey experiment (DSE), which was developed precisely for that purpose and captures the nature of the problem of distributional justice by accounting for the trade-offs that individuals are forced to make when allocating scarce resources. The DSE is a new survey experiment that measures people's justice attitudes in as direct and natural manner as possible, while minimising problems of social desirability bias. This paper focuses on showing and comparing three possible methods for analysing the data from the DSE and discussing its potential for distributive justice research.
\end{abstract}

Keywords: distributive justice, survey experiment, need, equality, merit 


\section{Introduction}

The struggle for social justice is a key force driving interactions between individuals, groups and institutions; shaping the progression of human history. What citizens perceive as just lays the foundation for the type of society they will strive to achieve. The reason for being in favour or against a certain change in policy, e.g. in taxation, highly depends on who will be affected by the ensuing redistribution how; and the importance we attach to different principles of justice (Mueller 1963; Faricy and Ellis 2014). This makes understanding the way people think about distributive justice fundamentally important for the social sciences. However, dissecting attitudes towards distributive justice, is a complex task which calls for a multidimensional approach. While traditionally, the question of distributive justice has predominantly been considered a domain of philosophers (Rawls 2005; Miller 2003; Sen 2009; Dworkin 2002; G. A. Cohen 1995; Nozick 2013), in recent decades, there has been a growing body of research that empirically assesses what people actually think about and feel in regard to questions of distributive justice. Among others, the topic has been studied by economists, (social) psychologists (M. J. Lerner and S. C. Lerner 1981), political scientists, social anthropologists and sociologists (Kluegel, Mason, and Wegener 1995; Ronald L Cohen 1986; Greenberg and Ronald L. Cohen 1982; Li and Tracer 2017).

In short, the empirical evidence shows that attitudes towards distributive justice are influenced on three levels: the individual, contextual and situational. Individual attributes such as gender and social class have an impact on what we perceive to be just (Robinson and Bell 1978; Shepelak 1989), but so does the context we grow up in. People's attitudes towards justice are affected by the societal order they live in, through both socialisation processes (J. P. Henrich, Fehr, and Gintis 2004; J. Henrich 2000) as well as status quo bias (Samuelson and Zeckhauser 1988). Furthermore, justice is situation-specific. Depending on the nature of the relationship we have with others and our collective goals, we refer to different justice principles to guide our behaviour (Deutsch 1975; Fiske 1992). 
While there has been a lot of work concentrating on either individual level or contextual factors (e.g. Alves and Rossi 1978; Arts and Gelissen 2001; Sauer et al. 2009), the role of the situation has largely been neglected. Additionally, it is important to be able to differentiate between the three most prominent principles of justice which are: need, merit and equality (Leventhal 1976; Arts and Gelissen 2001). However, the empirical work has been somewhat fractionated, with scholars often pitting just one principle against another, such as equality against equity (Leventhal, Popp, and Sawyer 1973; Liebig et al. 2015). Furthermore, a bulk of the experimental evidence has been based on student populations (e.g. Frohlich, Oppenheimer, and Eavey 1987b; Yaari and Bar-Hillel 1984; Scott and Bornstein 2009). As a consequence, we are far from having a deep-rooted understanding of how justice evaluations are formed.

By introducing the distributional survey experiment (DSE) as a new methodological approach, this paper attempts to contribute a tool that helps us disentangle the various factors influencing our perceptions of what a fair distribution is. The DSE is a new survey experiment which was specifically designed with the complex multidimensional structure of distributive justice in mind; it enables us to collect information on all three levels as well as on the three most relevant justice principles. The DSE combines some of the most useful properties of vignette experiments (otherwise known as factorial survey experiments) and choice experiments and allows us to collect data suited to the problem in a highly efficient way. The DSE is also unique in that it combines the possibilities of distributional games in laboratory settings with the efficiency and scope of a survey experiment. This is a fruitful mix and ensures both a high internal as well as external validity. The main achievement of the DSE, however, is that it captures the nature of the problem at hand in a way that was previously not possible. By letting respondents divide a prespecified amount of money among people described in vignettes, the DSE forces them to mentally go through an evaluation of the trade-offs between the three conflicting principles of need, equality and merit. As in real life, when it comes to the allocation of 
scarce goods, one person's gain is another's loss. Respondents thus reveal their implicit preferences without having to make any explicit statements or ratings, which would unnecessarily bring in social desirability bias and problems of multicollinearity (Rossi and Anderson 1982), in that we would not be able to analyse the relative importance of factors. The DSE thus makes it easier for us to disentangle the factors influencing justice evaluations on different levels.

Using the example of a distributional survey experiment in a setting in which money is allocated among friends, the paper will show three different strategies to analyse data from a DSE. The first approach is to treat the outcomes of the DSE as if they were generated in the context of a factorial survey. The second approach uses the information given through the interdependency of the three outcomes to rank the outcomes from lowest to highest. The third and most efficient approach, in that it uses a maximum of information, treats the outcomes as shares of the sum that was distributed.

In what follows, first a brief overview of the empirical literature on distributive justice is provided. This is followed by an introduction of the DSE as a new method, as well as of the three mentioned procedures to analyse the ensuing data. In a next step, the results of the different analytical strategies are compared. A discussion of the findings and their methodological implications concludes the paper.

\section{Background}

\subsection{Three Principles of Justice: Need, Equality and Merit}

When making a justice evaluation or more actively, allocating goods, people typically rely on one or a combination of justice principles: need, merit and equality to guide them and justify their choice (Leventhal 1976; Arts and Gelissen 2001). While under the need principle, a distribution is chosen that benefits those in need most (Braybrooke 1987), the merit principle favours those who are perceived to have in some way "earned" a reward. 
Throughout this paper, in the context of merit, I will refer to equity theory (or the theory of proportionality) (E. Walster, Berscheid, and G. W. Walster 1973; Homans 1974), and treat the terms merit, equity and desert as more or less interchangeable. These concepts all basically rely on the concept of proportionality, which postulates that individuals should receive outputs proportionally to the inputs they provided. Put differently, individuals should receive equal relative outcomes depending on their respective inputs. In a job setting, this input would typically be labour and in a more social setting, the input could be kindness (E. Walster, Berscheid, and G. W. Walster 1973). the output in the former case would be an appropriate wage, while in the latter, kindness could be repaid by help when in need. Under the egalitarian principle of equality on the other hand, there is no need to make distinctions between those in need and those who are deserving. Indeed, this would violate the equality principle; the basic assumption being that justice requires equal treatment. In essence, equality is an egalitarian concern that acknowledges the rights of humans to an equal share of resources in a society, on the sole basis of their being humans (Nielsen 1979; Lamont and Favor 2017). However, there is some discord in the literature with some authors equating need and equality with the argument that giving according to needs equalizes outcomes (e.g. Boulding 1988). For the sake of conceptual clarity, we will differentiate clearly between the principles of need and equality throughout the paper. The question that remains, however, is: when do we base our justice evaluations on which principles?

\subsubsection{Individual, contextual and situational factors influencing justice perceptions}

As previous research has shown, numerous factors on at least three different levels are relevant for the choice of justice principle we apply to allocation problems. First, on an individual level, different time-constant as well as time-varying factors shape our perceptions of distributive justice. Examples are gender and social class (Robinson and Bell 1978; Shepelak 1989) or experiences with social mobility (Piketty 1995). A large 
bulk of the literature points in the direction of self-serving assessments (Smith 1976; Sen 2009), with those worse off more in favour of a needs-based or egalitarian approach and those in more privileged positions advocating for an equity approach (Arts and Gelissen 2001; Konow 2001; Lewin-Epstein, Kaplan, and Levanon 2003; Shepelak 1989; d'Anjou, Steijn, and Van Aarsen 1995; Alves and Rossi 1978; Eek 1999; Robinson and Bell 1978; Boeri et al. 2001; Frohlich, Oppenheimer, and Eavey 1987a). Self-serving evaluations could also be caused by a desire to reduce cognitive dissonance, which arises in situations in which e.g. our actions conflict with our beliefs and attitudes, which causes uneasiness. By adjusting our attitudes to accommodate the behaviour in question, we can reduce the discrepancy and restore psychological balance (Festinger 1957).

Second, the context within which an individual is situated can shape the way he or she evaluates a situation and which allocation is deemed just. One of the obvious contextual differences is that of the country of residence, entailing many other contextual differences such as the way the society is organized (Arts and Gelissen 2001; J. P. Henrich, Fehr, and Gintis 2004), e.g. through differences in the respective welfare state situation (Arts and Gelissen 2001). As another contextual influence, Western societies and, due to globalization processes, a growing number of countries worldwide, are dominated by an individualistic capitalist philosophy. According to research on justice principles in social psychology, this favours the equity principle over the equality principle (Sampson 1975; Deutsch 1975). While equity involves individual agency and competition, equality considerations are inherent to systems that stress cooperation and collectivism, such as socialism (Sampson 1975; Hochschild 1981).

A third consideration, which has perhaps been neglected most by sociologists, but has received due consideration by social psychologists, is the situation in which goods are to be distributed (Deutsch 1975). This is because different situations provide people with different frames of reference. Proportionality is assumed to be the main principle in situations that are competitive, involve low interpersonal attachment, and in which 
productivity is the goal. The workplace is one such situation. Equality on the other hand, is assumed to be especially important in situations with a high group solidarity and a cooperative atmosphere, with harmony as an overarching goal. Relationships with friends and neighbours are a ready example of this type of situation. In yet another setting in which there is a high interpersonal attraction and attachment, including dependency, so that the well-being of those involved is of highest importance, need is assumed to be the most important principle of justice. Such a situation is often found in families (Deutsch 1975). There is empirical evidence showing that children too, seem to follow different cues depending on the situational framing. In an experiment, children allocated goods to their counterpart equally when the terms "team" and "partner" were made salient, and in accordance to equity theory when they perceived themselves as primarily responsible for only themselves (M. J. Lerner 1977).

If all these factors have an impact on what we perceive as a just distribution, the question arises, how the individual, contextual and situational factors come into play and influence which principles of justice will be applied.

\subsection{Hypotheses}

Given the broad implications of this theoretical and empirical background, and the methodological focus of this paper, it is necessary to focus on only a small piece of the puzzle. Although it is a key strength of the DSE that it enables us to collect data on the three principles and on the individual, contextual and situational levels simultaneously, we will concentrate on the DSE factors and the individual level in the context of Switzerland. Consequently, we will restrict the analysis to the situation of friends, in opposition to the work situation as the most common setting (Alves and Rossi 1978; Jasso 1978; Auspurg, Hinz, and Sauer 2017). On an individual level, we shall concentrate on the effects of social class but add gender and age as controls.

As mentioned, according to Deutsch (1975), allocating goods among friends is a situa- 
tion that favours the principle of equality, since the reference frame is that of a solidarityoriented group. If we take this very seriously, then the merit and need indicators shouldn't have any effects on the way the respondents distribute the money, but each vignette person should receive an equal split. Weakening this assumption, we would still expect the need and merit factors to matter, but just not as much as might be the case in other situations, that are, for example, more economically-oriented. However, for the purpose of this paper, we shall assume the strict interpretation and hypothesize that the need and merit factors will not have an impact on the way the sums are distributed. However, if we do find that need and merit matter all the same, on an individual level, we would expect class differentials. From a selfishness perspective and to avoid cognitive dissonance (Festinger 1957; Rabin 1995) and as has been found in past research mentioned above (e.g. Robinson and Bell 1978), we expect those from more privileged backgrounds to be less in favour of equal distributions and a needs-based approach and to place a higher value on merit instead. This means that an interaction effect between merit and class is expected, in the direction of a higher importance of merit for people from higher classes.

\section{Data and Methods}

This paper draws on data from Justice, an individual, contextual or situational affair? (JInCS), a project that aims to make a contribution towards a deeper understanding of questions of distributive justice. By including all three principles, need, merit and equality, and considering the individual, contextual and situational factors influencing justice evaluations, JInCS aims to crystallize general mechanisms behind justice evaluations. The project includes distributional survey experiments across four different situations (family, friends, workplace and public goods) using data from three different populations - Swiss general population as well as two student samples from the University of Bern and Princeton University for a cross-country comparison. In this paper, we will use the DSE in the friends situation using the Swiss population data. 
For the general population survey, the respondents were drawn from a stratified random sample (on the variables region, gender and age) from MS Direct, a marketing company with a large address register ${ }^{1}$. The Italian-speaking region was oversampled to allow for separate analyses.

Following Dillman's (2007) tailored design method (TDM), several measures were taken to raise the response rate of the participants. TDM is based on social exchange theory and rests on the assumption that by reducing the costs for the participants and increasing the benefits they acquire by participating in a survey, respondents are more likely to cooperate and provide the researchers with the data they need (Dillman 2007). To maximize response rates, the participants were contacted three times, to establish trust and to convince them of the importance of participating. First, they received a letter announcing that they had been randomly selected to participate in the survey. The second letter contained six documents. Next to the paper-pencil (PAPI) questionnaire, these were; an information letter with an individual code for online participation and a post-paid envelope to reduce the costs of participating. Also, the respondents received a card they could send back with their contact data if they wanted to be informed of the results. Further, as an incentive, two customized printed webstamps worth CHF 1.00 each as well as a thank-you-note to which the stamps were attached, were included. On the whole, with a response rate of $40 \%^{2}$, the measures seem to have paid off.

The distributional survey experiments make up the core of the JInCS project and were placed at the beginning of the survey, directly after the ice breaker question. The reason for this early placement was so that the respondents performed the cognitively taxing distributional task before the onset of fatigue. After the four experiments, the respondents were also asked a series of other questions on issues of distributive justice. Furthermore, at the end of questionnaire, the respondents were asked for some sociodemographic information. 


\subsection{The distributional survey experiment}

Since questions of distributive justice can be considered a sensitive issue from an ethical and political point of view, it is important to think about social desirability bias when collecting the data. Survey experiments are a powerful tool for reducing social desirability bias (Auspurg, Hinz, and Sauer 2015). One mechanism through which this is achieved is the indirect nature of the question (Alexander and H. J. Becker 1978; Auspurg and Hinz 2015a). Also, the dimensions of interest are not brought to the attention of the respondents explicitly, but only indirectly as part of a whole description, potentially making respondents less aware of the experimental context. Evaluating characteristics in bundles, as is the case of survey experiments, thus makes the situation more lifelike and lowers the potential for social desirability bias (Alexander and H. J. Becker 1978; Wallander 2009).

Another advantage of survey experiments is their efficiency. The researcher can manipulate several treatments in one experiment. However, to not overburden the respondent, researchers should restrict the number of dimensions to seven $(+/-2)$ (Auspurg and Hinz 2015a). Furthermore, survey experiments combine the advantages of conventional population-based surveys and experiments (Angrist and Pischke 2009; R. Becker and Zangger 2015). Survey experiments are more economical than many other experiments and can easily be distributed to a large population in a paper-pencil or online questionnaire. The larger scale dissemination compared to laboratory experiments is valuable in terms of external validity. And on another level, survey experiments have the valuable property of circumventing the problem of multicollinearity of different dimensions (Rossi and Nock 1982; Badgett and Folbre 2003). By using efficient designs, in which the dimensions that make up a vignette are brought into a nearly orthogonal array, this is no longer a problem . We can easily analyse how the dimensions compare and which relative importance they have for the overall assessment (Rossi and Anderson 1982). Another major advantage of survey experiments is that, since they are embedded in a PAPI or 
online questionnaire, other variables such as from the socio-demographic section can be included in the analysis of the experiment.

As a survey experiment, the distributional survey experiment incorporates all these properties. The main new element compared to the three most common types of survey experiments, such as discrete choice experiments (DCE), factorial survey experiments (FSE) and conjoint analysis (CJA) (Auspurg and Hinz 2015b), is the nature of the task. Since from a social science point of view, CJAs lack a solid theoretical foundation but rely on a purely mathematical one, and are predominantly used in marketing research, this subtype shall not be discussed further (Louviere, Flynn, and Carson 2010). In factorial surveys, respondents are presented one or many vignettes and they are asked to rate each of them on a scale (Auspurg and Hinz 2015a). In choice experiments on the other hand, the respondents are shown a collection of typically three vignettes as a group, of which respondents choose their preferred alternative (Street, Burgess, and Louviere 2005). The DSE combines the advantageous properties of both approaches but adds a new element by asking the respondents to distribute a prespecified sum among three people (of course this number can be modified) described in vignettes. This is a more active task and captures the relevant evaluative processes involved in justice considerations better than the rating of single vignettes or the choice of one alternative from a group. As in real life, to achieve a distribution deemed just, the DSE requires respondents to weigh the trade-offs between the different justice principles. When one person is assigned a larger portion of the sum, the other two people automatically have less left over. To account for this interdependency, the DSE is technically set up as a choice experiment. This way, the three vignette people are bundled into choice sets to ensure that the dimensions are arranged efficiently, with maximized orthogonality and level-balance, across the three vignettes. While the DSE thus gives us the visual presentation and the interdependency of a choice experiment, we also have the convenient metric outcomes comparable to that from factorial surveys. However, as mentioned before, the biggest advantage, is 
that it does more justice to the nature of the problem, than either a factorial survey, choice experiment or the typical laboratory experiment on distribution, by creating a situation in which respondents are forced to undergo the process of evaluating the tradeoffs between the justice principles. As in real life, the respondents must judge what is the fair share for individuals displaying a specific mix of attributes that trigger different and often conflicting impulses, so that, for example, a person who is needy, might not be very meritorious. Furthermore, factors that have nothing to do with merit or need, such as ethnic origin, might have an effect on our justice evaluation, such as when we prefer our in-group to our out-group (Allport 1979) and thus feel as if an out-group person should get less than an in-group person independent of their contributions and their life situation. The DSE creates a situation in which respondents have to evaluate three people as a whole, with their individual combination of attributes. With a factorial survey experiment, it would be possible to create this situation in which respondents have to decide how much a person should receive based on a combination of attributes; however only for one person at a time. Because of this limitation, the factorial survey experiment fails to account for the fact that one person's gain is another's loss. In real life, we are simply rarely in a situation in which there is no limit on the goods we are asked to distribute among people and problems of distributive justice are especially relevant in cases in which we cannot give everyone as much as we would ideally like to, but have to prioritize.

What's more, to achieve an allocation of goods they think is fair, respondents have to evaluate the relative standing of the vignette people compared to the other two people in the choice set. This interdependency would also have been accounted for in a choice experiment, in which a respondent could choose the person that overall seems most worthy of being given the reward. However, a DSE is arguably psychologically more satisfactory for the respondents, since it allows them to differentiate more and to give something to everyone if they think that's the fairest option, while allowing them to 
apportion the resources in a preference order preserving way. They can simply give the person with the most desirable combination of attributes most and then divide what remains between the two other people, of which, again, one might be regarded as having a legitimate claim to a larger portion of the goods than the other. However, the case for the DSE becomes especially apparent when we think of radical egalitarians. For them, it is never possible to reveal their preference when forced to make a justice evaluation on a scale or to pick one individual over the other two. The DSE offers the respondents with much more freedom to distribute in line with their underlying preferences. On top of that, the flexibility and adaptability of the DSE enable us to measure and take into consideration the complex interplay of individual-level, contextual and situational factors that influence justice evaluations. By distributing the same DSE in different contexts, such as countries, we can find out how much variance in justice evaluations is due to contextual factors. By embedding the allocative tasks in different settings, such as the workplace or in families, we can find out how different situations and frames influence our sense of justice. The DSE is thus a highly valuable tool for the collection of data on distributive justice. It provides the researcher with data that more precisely depicts the real-life trade-offs that people are forced to make when considering questions of distributive justice.

\subsubsection{The Design of the Distributional Survey Experiment}

For the situation of an allocative problem among friends, a distributional survey experiment including the descriptions of three hypothetical friends in the form of vignettes was designed. The vignettes consist of nine dimensions with two or three levels each. All two-way interactions between the dimensions were included in the design. In the end, an experimental design consisting of 144 vignettes arranged in 48 choice sets in groups of three and with a relative D-efficiency of 93 was chosen.

Table 1 gives an overview of the characteristics/dimensions and their levels included in 
the DSE. Of the nine dimensions included in the vignettes, four stand for need: whether they live with a partner or not and whether they have children or not. Furthermore the information was included whether they are in good or bad health and whether they are in a easy or tight financial situation. Three variables symbolise merit: whether one can always count on the friend or only in good times, whether they are completely trustworthy or not and how long they have been friends for (ranging from 2 to 14 years). In order to save space and to facilitate legibility, the values of these variables were taken together to form the variable merit for the analysis in the models including respondent level variables. The variable merit, built with this additive scale ${ }^{3}$ has values ranging from 3 (lowest levels of merit) to 7 (highest values of merit). The same was done for the need variables, resulting in a variable named need, with values ranging from 4 (lowest levels of need) to 8 (highest levels of need). The name of the person described in the vignette operationalised two constructs at the same time: their gender and ethnic origin. These two dimensions were added as a means of giving the respondents enough information and also so as to be able to test whether people discriminate by gender and ethnicity.

Table 1: Characteristics Included in the DSE in the Friend Situation

\begin{tabular}{ll}
\hline \hline Characteristics & Values \\
\hline Gender & 1 male, 2 female \\
Ethnic origin & 1 Swiss name, 2 Slavic name, 3 Arabic name \\
Need & 1 lives with spouse/partner, 2 single \\
Private life & 1 no children, 2 two children \\
Children & 1 in good health, 2 in poor health \\
Health & 1 easy, 2 tight \\
Financial situation & 1 a good friend when times are good, \\
Merit & 2 you can count on them when times are rough \\
Reliability & 1 you better watch out, what you tell them, \\
& 2 you can trust them with anything \\
Trustworthiness & 2 years, 8 years , 14 years \\
& \\
Friends since & $3,000,9,000,18,000,30,000$ \\
Additionally randomised per DSE & \\
money to be distributed in CHF &
\end{tabular}


Additionally, the sum to be distributed varied randomly between the choice sets, with either CHF 3,000, CHF 9,000, CHF 18,000 or CHF 30,000. The sums were altered so as to be able to evaluate the effects of the size of the sum on the applied justice principles. In general, any kind of resource that can be apportioned could be used in the DSE, however, monetary resources were chosen for several reasons. Next to it being a convenient metric for analysis, money is a quantity respondents are familiar working with and it allows them to subdivide the amount to achieve as proportionally small or large shares as they please. This allows respondents much freedom in expressing their preferences. Furthermore, in the friend situation, the framing of the experiment was as follows: Respondents were told to imagine having won a large sum in the lottery and that to celebrate, they were going to give a small fraction of the sum to three of their friends. Respondents were specifically asked to subdivide this sum among the three friends whichever way they wanted. The instructions included a note that this included the possibility of giving everything to one person and nothing to the other two, just as much as splitting the sum equally among the three. ${ }^{4}$

\subsection{Sample and Operationalisation of the Respondent Variables}

Table 2 gives an overview of the sample in terms of gender, class and age of the respondents. The distribution of men and women is nearly equal, with a slight majority of women. The respondents' class was constructed via the ISCO-08 classification of their occupation which was then converted into the Erikson-Goldthorpe-Portocarero (EGP) class scheme (Erikson and Goldthorpe 1992). The five categories of the EGP-class as shown in table 2 were chosen so as to obtain similarly sized groups. In the Swiss situation, the high number of high class respondents is rather representative (FSO 2020). Age was also categorised so as to have sufficiently large and comparably sized groups. 
Table 2: Descriptive Statistics of Respondents

\begin{tabular}{llcc}
\hline \hline Variable & Value & N & \% of total \\
\hline Gender & men & 696 & 47 \\
& women & 780 & 53 \\
\hline EGP-class & EGP I & 380 & 26 \\
& EGP II & 422 & 29 \\
& EGP IIIa & 264 & 18 \\
& EGP IIIb - EGP V & 234 & 16 \\
& EGP VI - EGP VIIb & 177 & 12 \\
\hline age & $17-30$ & 196 & 13 \\
& $31-40$ & 248 & 17 \\
& $41-50$ & 252 & 17 \\
& $51-60$ & 301 & 20 \\
& $60-70$ & 246 & 17 \\
& 71 plus & 234 & 16 \\
\hline \hline Total & & 1476 & 100 \\
\hline
\end{tabular}

\subsection{Analytical strategies}

The DSE yields three metric outcomes, representing the sums that were apportioned to the vignette people, per respondent. Before analysis, the data must be brought into a long format, so that for each DSE we have the treatments from the experimental setup (levels of the dimensions) and the respective outcome variable in three separate rows per respondent. Since the size of the sum is not relevant for our purposes here, we can ignore the additional information of the amount and use the z-standardized outcomes. In the following, three possible strategies for analysing the data from the DSE are summarized. However, since the data has a multilevel structure in all cases, we shall look ways of accounting for it first. 


\subsubsection{Considering the multilevel structure}

Since the DSE yields data on two levels with the variables of the experimental setup on level 1 and the respondent characteristics on level 2, we need multilevel models. Equation (1) is a linear multilevel model for a set of individuals $i$ (level 2), for which we typically have more than one observation $j$ (level 1), which in our case correspond to multiple vignettes per respondent.

$$
y_{i j}=\mu_{j}+\beta x_{i j}+\gamma z_{i}+\alpha_{i}+\varepsilon_{i j}
$$

The constant $\mu_{j}$ is allowed to vary by observation/vignette, the regression coefficients are given by $\beta$ for the DSE dimensions $x_{i j}$, which vary between and within individuals, and $\gamma$ for the respondent-level predictors $z_{i}$ (varies only between individuals/clusters). We also have two error terms; $\alpha_{i}$ is a constant that varies over individuals but not over observations (level 2 error) and $\varepsilon_{i j}$ which varies randomly by individual as well as by observation/vignette. Depending on whether we are estimating a fixed effects or random-effects model however, we rely on different underlying assumptions for $\alpha_{i}$. In the fixed effects models $\alpha_{i}$ represents all unobserved respondent level variables, and as such is allowed to be correlated with the DSE dimensions $x_{i j}$ and, also the respondent characteristics $z_{i}$ (Allison 2009; Schunck 2013). This latter property is at once the main strength and "weakness" of the fixed-effects model. Since we are controlling for all individual-specific variation, both observed and unobserved, we can make a causal claim. However, if we are interested in the coefficients for $z_{i}$, we have to use other models, since the fixed effects model cannot provide estimates for respondent level variables. The random effects model "solves this problem", if we look at it as such, by assuming that $\alpha_{i}$ represents just another source of random variation, a set of random variables, that have a prespecified probability distribution. This entails the assumption that the individual error term $\alpha_{i}$ is uncorrelated with all other independent variables as well as with the error 
term $\varepsilon_{i j}$. If this assumption holds true, it gives us unbiased estimates and the model is more efficient than the fixed-effects model. Luckily we can easily test whether this is the case, using either the Hausman test ${ }^{5}$ or by comparing the within and between effects of a hybrid model (Allison 2009; Firebaugh, Warner, and Massoglia 2013). If the clusterspecific error term proves not to be random after all, the estimates from the random effects model will be biased. The hybrid model is very convenient in that it allows us to combine the best traits of fixed and random effects models, thus making it possible to combine the efficacy of a random effects model and the consistency of a fixed effects model. Hybrid models are in essence random effects estimations that include unit fixed effects (Schunck 2013). By demeaning or centering the observation-specific variables, that is, by calculating unit-specific means and then calculating the deviation scores from the means for the single values, we can decompose the effects of observation-specific variables into within and between variance. We can then add these within and between effects to our random effects model, in which we also include the respondent-level variables (Allison 2009; Schunck 2013). For ordinal outcome variables, we can either include these within and between effects in a multilevel mixed-effects ordered logistic regression or more directly: with xthybrid, a user written Stata command based on generalized linear mixed models (GLMM) (Schunck and Perales 2017). In the following, three suggested methods for analysing the DSE are introduced.

\subsubsection{Method 1: Treating the Outcomes of the DSE as Independent Metric Outcomes}

Perhaps most straightforwardly, the outcomes from the DSE can be treated as if they had resulted from a factorial survey experiment, that is to say, as independent from one another. Since each respondent distributed money among three friends, we have three observations that serve as our dependent variables, per respondent. The levels, e.g. male/female, of the vignette variables are the explanatory variables. Given that the 
variables in the vignettes are uncorrelated by design and the survey experiments were randomly allocated to the respondents, regressing the received amount on the vignette dimensions reveals their causal effects. However, to account for the fact that one and the same person was responsible for the distributions among the three vignettes of a DSE, and that these distributions are interdependent, a multilevel model is recommended. As described above, the choice of model — random effects, fixed effects or hybrid — depends on the data at hand and the intention of the researcher. While a multilevel model does take into account that the three outcomes of a DSE depend on the person making the distribution, we have a further interdependence in the data structure, that we haven't accounted for yet. Additionally to being directly influenced by the treatments and a respondent's particular views on distributive justice, the three outcomes of the DSE are also interdependent by design in that the task consists of dividing a sum among the three vignettes. Ignoring this would be to ignore one of the greatest advantages of the experimental design. To treat the resulting interdependency as substance rather than nuisance (Beck and Katz 1996; Glick and Roberts 1984; Zangger 2019; Franzese and Hays 2008), we should go a step further, such as by using one of the two following methods.

\subsubsection{Method 2: Treating the outcomes of the DSE as ranks}

As a possibility to account for the design-inherent interdependency of the individual results for each vignette, we can rank the outcomes. The outcome variable was modified so that the person who received most was assigned a 3 , the person who got the lowest score received a 1 and the person in between scored a 2 . If everyone got the same amount, then everyone was assigned the highest value. Because this approach yields ordinal dependent variables, this should be accounted for in the choice of estimation model (e.g. Stata's meologit or the user written xthybrid). In contrast to the first approach, this procedure ensures that the relation between the bundles of levels of the characteristics making up the single vignettes are regarded in comparison with one another. Instead of the 
individual amounts, in this case the stress lies on the individual positioning of the vignette people, which is closer to what we need from the point of view of theory. However, on the downside, when converting the outcome variable to create ranks, we also lose some information on the magnitude of the effects, since ranking gives the impression of equal distance between outcomes, while in reality, e.g. two outcomes might be very close together with a large difference to the outcome ranked third. The approach introduced next tries to take this into consideration and exploit the full information potential of the DSE.

\subsubsection{Method 3: Treating the outcomes of the DSE as shares}

A third method that can be used to analyse data from a DSE, that acknowledges the interdependence of the outcomes but also uses the data to its full potential, is to treat the outcomes of the single vignettes as shares of the original sum that was distributed. This method incorporates elements of both the aforementioned analytical strategies. On the one hand, information on the rank is implicitly included. On the other hand, the method allows for a higher exploitation of the information at hand compared to regarding the single outcomes as independent from each other or using ranks. The advantage of using shares instead of ranks is that the magnitude of the differences between the sums is taken into consideration. In sum, this approach makes the most of the available information. It automatically incorporates the element of interdependency, in that the shares, just like ranks, include information on the relation to the other vignettes portrayed in the DSE. As mentioned, the exact share holds more information than just the rank of the vignette person. And all this is more informative than the first approach, because the latter ignores the interdependence of the distributed sums caused by the different sets of characteristics of the vignette people. This third approach is thus also the method with the highest statistical power and smallest standards errors. In addition, it is most in line with theoretical considerations, since it best illustrates the fact that a sum had 
to be subdivided among three people, where each individual outcome automatically and intendedly affects the other two.

\section{Results}

As a first step, we shall see how the different methods compare when looking at how the vignette dimensions influence the distributions the respondents made. As a second step, we add the respondent level variables to see whether participants differ in their views on how to achieve a just distribution depending on their gender, age and social class. However, to guide us in our choice of model, computing a Hausman test is recommended. The test-statistic shown in table 3 is the result of a comparison of a fixed effects and random effects model computed using share as the outcome variable. We see that the Hausman test is significant, indicating systematic differences between the fixed effects and random effects model so that a random effects model would lead to biased estimates (Rabe-Hesketh and Skrondal 2012; Schunck 2013; Allison 2009). This finding is replicated with the first approach that treats the outcomes as independent (results not shown) and leads to the same conclusion.

Table 3: Model specification test

\begin{tabular}{lcr}
\hline \hline Test & Test statistic (df) & $p$-value \\
\hline Random vs. fixed effects (Hausman) & $199.07(9)$ & 0.0000 \\
\hline \hline
\end{tabular}

This is why, for the models including just the DSE variables, shown in table 4, the fixed effect model was used for the first and third approaches. The fixed effects models were computed using Stata's xtreg command with the fe (fixed effects) option, the respondent ID serving as the panel variable. For the models including the class and merit interaction, the fixed effects approach was used again for the first and third approaches. Since the second approach using ranks leads to an ordinal-scaled dependent variable, a multilevel mixed-effects ordered logistic regression was computed using Stata's meologit command. 
To obtain unbiased estimates, both the model including just the level one variables as well as the model with respondent variables, contained within and between effects. However, since the between effects are of no substantial interest here and are not very informative, they have been omitted in the tables (Allison 2009; Schunck 2013; Schunck and Perales 2017).

\subsection{Level 1: The effects of the dimensions of the DSE}

Table 4 shows the results of three multilevel models. The first column shows the results using the first approach, which treats each single outcome of the DSE as an independent outcome (method 1). To account for the fact that one and the same respondent was responsible for the three outcomes of the DSE a fixed effects model was estimated. The z-standardised sum that each vignette person got was the dependent variable. One way of thinking about it, is as if the single outcomes stemmed from vignettes of a factorial survey experiment. At a first glance, we see that all the dimensions of the DSE had a highly significant effect on the outcome except for gender. People with a Slavic or Arabic name received significantly less than those with a Swiss name. Turning our attention to the variables representing need, we see that they all had an effect in the expected direction. Those who are single and don't live with a partner and those who have children receive higher sums than those who live with their partner/spouse and those who do not have children. Furthermore, the hypothetical friends who have health problems and are in a difficult financial situation receive more than those who are healthy and not struggling financially. Merit matters as well. Friends one can count on when times are rough, and those one can really trust, receive more than those who are less reliable and trustworthy. We also find that loyalty pays off, with those who have been friends for a long time, receiving more than friends one has not known that long yet.

The second column in table 4 displays the results using ranks as the dependent variable (method 2). To account for the nested structure of the data and the ordinality 
Table 4: Distributing Money Among Friends — DSE and Respondent Variables

\begin{tabular}{|c|c|c|c|}
\hline & Independent & Ranks & Shares \\
\hline \multicolumn{4}{|l|}{ Level 1: Within effects } \\
\hline \multicolumn{4}{|l|}{ Gender (Ref.: $\operatorname{man})$} \\
\hline woman & $\begin{array}{c}-0.012 \\
(0.023)\end{array}$ & $\begin{array}{c}-0.096 \\
(0.070)\end{array}$ & $\begin{array}{c}0.001 \\
(0.006)\end{array}$ \\
\hline \multicolumn{4}{|l|}{ Ethnic Origin (Ref.: Swiss name) } \\
\hline Slavic name & $\begin{array}{c}-0.099^{* * *} \\
(0.026)\end{array}$ & $\begin{array}{c}-0.145^{+} \\
(0.083)\end{array}$ & $\begin{array}{c}-0.010 \\
(0.007)\end{array}$ \\
\hline Arabic name & $\begin{array}{c}-0.145^{* * *} \\
(0.026)\end{array}$ & $\begin{array}{c}-0.217^{* *} \\
(0.081)\end{array}$ & $\begin{array}{c}-0.018^{* *} \\
(0.007)\end{array}$ \\
\hline \multicolumn{4}{|l|}{ Private Life (Ref.: lives with spouse/partner) } \\
\hline single & $\begin{array}{l}0.111^{* * *} \\
(0.023)\end{array}$ & $\begin{array}{l}0.398^{* * *} \\
(0.071)\end{array}$ & $\begin{array}{l}0.038^{* * *} \\
(0.006)\end{array}$ \\
\hline \multicolumn{4}{|l|}{ Children (Ref.: no children) } \\
\hline 2 children & $\begin{array}{l}0.369^{* * *} \\
(0.023)\end{array}$ & $\begin{array}{l}1.327^{* * *} \\
(0.076)\end{array}$ & $\begin{array}{l}0.083^{* * *} \\
(0.006)\end{array}$ \\
\hline \multicolumn{4}{|l|}{ Health (Ref.: in good health) } \\
\hline in poor health & $\begin{array}{l}0.284^{* * *} \\
(0.023)\end{array}$ & $\begin{array}{l}1.129^{* * *} \\
(0.075)\end{array}$ & $\begin{array}{l}0.082^{* * *} \\
(0.006)\end{array}$ \\
\hline \multicolumn{4}{|c|}{ Financial situation (Ref.: easy financial situation) } \\
\hline tight financial situation & $\begin{array}{l}0.359^{* * *} \\
(0.023)\end{array}$ & $\begin{array}{l}1.508^{* * *} \\
(0.078)\end{array}$ & $\begin{array}{l}0.116^{* * *} \\
(0.006)\end{array}$ \\
\hline \multicolumn{4}{|c|}{ Reliability (Ref.: a good friend when times are good) } \\
\hline you can count on they when times are rough & $\begin{array}{l}0.370^{* * *} \\
(0.023)\end{array}$ & $\begin{array}{l}1.270^{* * *} \\
(0.077)\end{array}$ & $\begin{array}{l}0.093^{* * *} \\
(0.006)\end{array}$ \\
\hline \multicolumn{4}{|c|}{ Trustworthiness (Ref:: you better watch out what you tell them) } \\
\hline you can trust them with anything & $\begin{array}{l}0.121^{* * *} \\
(0.023)\end{array}$ & $\begin{array}{l}0.923^{* * *} \\
(0.073)\end{array}$ & $\begin{array}{l}0.078^{* * *} \\
(0.006)\end{array}$ \\
\hline \multicolumn{4}{|l|}{ Friends since (Ref.: been friends for 2 years) } \\
\hline been friends for 8 years & $\begin{array}{l}0.122^{* * *} \\
(0.026)\end{array}$ & $\begin{array}{l}0.455^{* * *} \\
(0.080)\end{array}$ & $\begin{array}{l}0.029^{* * *} \\
(0.007)\end{array}$ \\
\hline been friends for 14 years & $\begin{array}{l}0.242^{* * *} \\
(0.026)\end{array}$ & $\begin{array}{l}1.014^{* * *} \\
(0.086)\end{array}$ & $\begin{array}{l}0.060^{* * *} \\
(0.007)\end{array}$ \\
\hline constant & $\begin{array}{c}-2.434^{* * *} \\
(0.089)\end{array}$ & & $\begin{array}{c}-0.424^{* * *} \\
(0.022)\end{array}$ \\
\hline ID(constant) & & $\begin{array}{l}0.666^{* * *} \\
(0.124) \\
\end{array}$ & \\
\hline$R^{2}$ between & 0.052 & & 0.003 \\
\hline$R^{2}$ overall & 0.075 & & 0.274 \\
\hline$R^{2}$ within & 0.266 & & 0.323 \\
\hline$N$ & 4428 & 4428 & 4428 \\
\hline
\end{tabular}

Standard errors in parentheses 23

${ }^{+} p<0.10,{ }^{*} p<0.05,{ }^{* *} p<0.01,{ }^{* * *} p<0.001$ 
of the dependent variable, a multilevel mixed-effects ordered logistic regression model using Stata's meologit command and including the centered/demeaned variables ${ }^{6}$ was estimated. The demeaned variables, here under the subtitle Within effects, are equivalent to fixed effect estimates. The between effects, or unit-specific means, which need to be included in the model for consistency are not displayed, since they are not very accessible in themselves (Schunck 2013; Schunck and Perales 2017). This approach bears the advantage that the information from the interdependency of the three outcomes per DSE is explicitly used in the estimation. However, the obtained results do not differ substantially from those in the previous model. The most important difference is that there is only a marginally significant negative effect of a Slavic name compared to a Swiss name.

The third column in table 4 shows the results obtained through treating the single outcomes of the DSE as shares (method 3) and again, using a fixed effects approach. This third method combines both principle advantages of the two aforementioned approaches. By treating the single outcomes as shares of a whole, the third approach acknowledges the interdependency of the outcomes across a choice set, while exploiting more information than the method using ranks, since it allows for a more fine-grained illustration of the underlying preferences. Once again, the results are very similar in direction and significance of effects to those from the preceding two models. Just as in the method using rank as the dependent variable, an Arabic name carries a significant disadvantage. Needier and more meritorious friends receive a larger share of the pie while again gender has no effect on the distribution. To illustrate: Adding up the effects of the vignette dimensions, we see that on average, a male Swiss friend with the highest values of need and merit would receive $61 \%$ of the share. A female friend with an Arabic name and with the lowest levels of need and merit would receive $5 \%$.

Summing up, in a situation in which money is distributed among friends, need as well as merit considerations have an effect on the distribution. Apart from that, if the friend 
in question has a foreign name (Arabic across all models and Slavic in models 1 and 2), they receive less money, suggesting that a bias is at play that leads to discrimination. Furthermore, over all three models, the results are rather comparable, with the biggest difference being in the effects of ethnic origin. However, comparing the model fit of model 1 and 3 , which were both obtained through fixed effects regressions, we see a difference to the advantage of the method using shares. The overall and the within R-squared are both substantially higher in the models using shares compared to the first method. This was to be expected from a methodological point of view, since the method most efficiently accounts for the interdependency of the outcomes of a DSE and incorporates it in the model estimation. Expressing the outcomes as share at the same time makes most of the available information and treats the interdependency as substantially relevant.

\subsubsection{Relative Importance of Factors}

To compare the three methods with regard to the relative importance of the DSE factors, we can run the same models again, but this time with with centered explanatory variables. Table 5 shows the results using the three methods. Now that the variables are centered, the highest effect sizes can be interpreted as the variable with the highest relative importance for the overall prediction. While there is a large overlap of the results from the three methods, there are still some differences in the ordering. While the need variables children and financial situation and the merit variable reliability are the three most important variables independent of the method used, the first model suggests that with reliability, merit is the most important factor, while the other two methods have financial situation, indicating need, as the topmost important variable. For illustrative purposes, we will take a closer look at the third model.

The results from the third model suggest that in the situation of distributing money among friends, the financial circumstances, which is perhaps the most obvious indicator of need, has the strongest effect on the share a person receives. However, the second 
Table 5: Relative Importance of Factors in the Friends Situation

\begin{tabular}{lccc}
\hline & Independent & Ranks & Shares \\
\hline Gender & -0.007 & -0.046 & 0.000 \\
Ethnic Origin & $(0.011)$ & $(0.034)$ & $(0.003)$ \\
Private Life & $-0.059^{* * *}$ & $-0.083^{*}$ & $-0.007^{* *}$ \\
& $(0.011)$ & $(0.033)$ & $(0.003)$ \\
Children & $0.055^{* * *}$ & $0.178^{* * *}$ & $0.019^{* * *}$ \\
& $(0.011)$ & $(0.034)$ & $(0.003)$ \\
Health & $0.184^{* * *}$ & $0.601^{* * *}$ & $0.042^{* * *}$ \\
& $(0.011)$ & $(0.037)$ & $(0.003)$ \\
Financial situation & $0.142^{* * *}$ & $0.504^{* * *}$ & $0.041^{* * *}$ \\
Reliability & $(0.011)$ & $(0.036)$ & $(0.003)$ \\
& $0.179^{* * *}$ & $0.669^{* * *}$ & $0.058^{* * *}$ \\
Trustworthiness & $(0.011)$ & $(0.038)$ & $(0.003)$ \\
& $0.185^{* * *}$ & $0.592^{* * *}$ & $0.046^{* * *}$ \\
Friends since & $(0.011)$ & $(0.037)$ & $(0.003)$ \\
& $0.060^{* * *}$ & $0.418^{* * *}$ & $0.039^{* * *}$ \\
& $(0.011)$ & $(0.036)$ & $(0.003)$ \\
& $0.099^{* * *}$ & $0.411^{* * *}$ & $0.024^{* * *}$
\end{tabular}

Standard errors in parentheses

$N=4,428$

${ }^{+} p<0.10,{ }^{*} p<0.05,{ }^{* *} p<0.01,{ }^{* * *} p<0.001$ 
most important factor is the reliability of a friend, an indicator of merit. This is again followed by the need indicators number of children and health status. Trustworthiness and length of friendship, as further indicators of merit, are next in line. Whether the friend in question lives with a partner or not is less relevant and ethnic origin, which was added to test for discrimination effects, is the least important variable. Gender has no significant influence. So while, with financial situation, an indicator of need is the most relevant variable for the just allocation of goods in the friends situation in the context of Switzerland, merit is important too and, even if the effects are not large, discrimination comes into play as well. If we understand equality in the strict sense of the word, we can thus reject the hypothesis claiming that people distribute equally among friends, since we found merit and need as well as ethnic origin to have effects on the chosen distributions.

\subsection{Adding Respondent Characteristics}

To test whether our hypothesis of class dependent distributions holds, we add the interaction of a respondents' social class and the merit of the hypothetical person to the models. We also include gender, age and social class as controls in the model using rank as the outcome variable. Since equal sums were assigned the same next highest values (a 3 for each outcome if the respondent split the sum equally between the hypothetical friends, as opposed to a $3 ; 2 ; 1$ outcome if every person was apportioned an unequal amount), a positive effect signifies a tendency for equal distributions. We do not include the respondent variables as main effects in the models using the independent outcome approach or the third method that treats the outcome as shares, because they would not have any substantial meaning under these methods. For model 2 of table 6 , which used rank as the dependent variable, once again a multilevel mixed-effects ordered logistic regression with cluster mean centered level-one variables (demeaned level-one variables) was estimated. This time, the respondent variables as well as the interaction terms of respondent's class and merit were added to the model (Schunck 2013). 
As mentioned before, to facilitate legibility, the merit and need variables were summed up in a single additive scale for merit and need respectively. The interaction effects between a respondent's EGP as an indicator of class origin and merit were then constructed and added to the model.

As table 6 shows, including the interaction effect of a respondent's class and the merit variable yields very similar results to those obtained in the models including just the DSE variables (level one). In model 1 of table 6 , showing the results of a fixed effects model treating the outcomes of the DSE as independent of one another, we see that on level one, all the characteristics of the DSE, apart from gender and the interaction effects of merit and class, have a significant impact on the distributed amount of money. We still see significant differences between friends with foreign sounding names and the new need and merit variables retain the expected effects: the needier and the more meritorious, the more the hypothetical friends receive. However, the interaction of merit and social class, which was the main motivation for the new models, has no significant effects.

The results of the second method of analysis, which assigned ranks to the outcomes of the DSE are shown in the second model in table 6. As mentioned above, the results were obtained using a multilevel mixed-effects ordered logistic regression with centered/demeaned variables. On the whole, the results are similar to those obtained from the first approach. However the interaction term of merit and social class becomes marginally significant for one case. The middle EGP group (EGP IIIa) gives more to those with a higher merit than those from the highest EGP group. This contradicts our expectation. An advantage of this method is that the level 2 variables can be interpreted substantially as well. We see a (marginally) significant positive effect for women and for the lowest EGP group, and a marginally significant negative effect for the second highest EGP group. In the case of ranks, and the way it was operationalised here ${ }^{7}$, the positive effect for women and the lowest EGP group means a higher propensity for more equal outcomes. When two or three of the hypothetical friends receive the same amount, 
The Distributional Survey Experiment - Introducing a New Method for the Assessment of Attitudes Towards Distributive Justice

Table 6: Distributing Money Among Friends - DSE and Respondent Variables

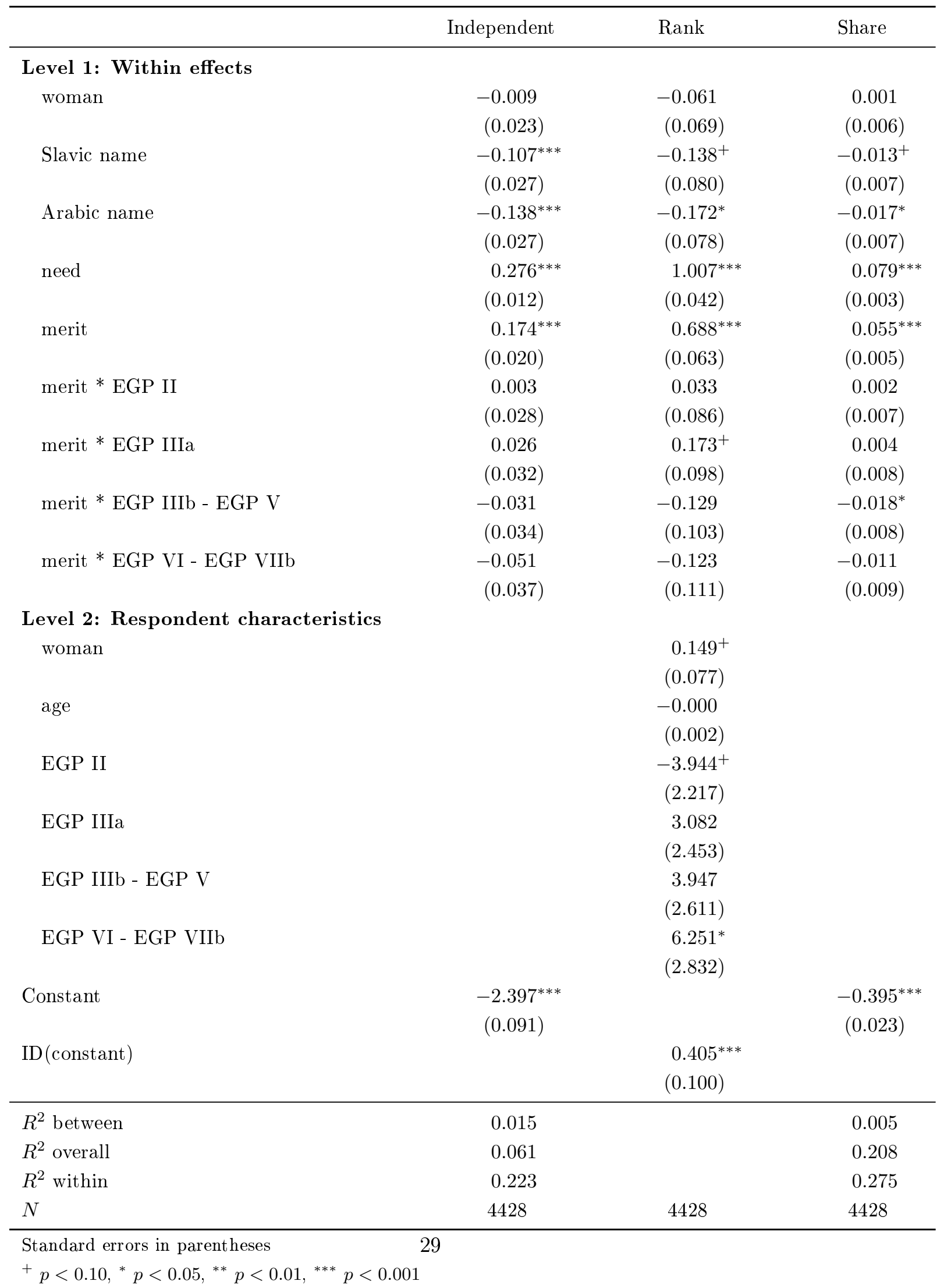


less people get lower ranks, leading to a greater number of values 2 and 3 compared to 1. This suggests that women and respondents from the two lowest EGP groups were more prone to distributing the sums equally among the hypothetical friends than men and higher class respondents. But also, that the second highest EGP group is slightly more likely to distribute less equally than the highest group. This also brings us to a key advantage of the method by ranks. By assigning ranks to the single vignettes, we can gain some information on the extent to which respondents distributed equally ${ }^{8}$, such as is not possible with either of the other two methods that treat the outcomes as though they were obtained from a factorial survey experiment or portrayed as shares.

The third model of table 6 shows the results from a fixed effects model with the outcomes depicted as shares of the total sum that was distributed by the respondents. Once again, the effects for the level 1 variables remain unchallenged for the DSE variables. The main difference for the level one variables is that the interaction effect between EGP class IIIa and merit shown in the previous model is no longer significant using this third procedure but the interaction effect of merit and class is significantly negative for the second lowest EGP category compared to the highest EGP class. This is an effect in the expected direction, with people from lower social classes caring a little less about merit than people from higher classes.

Summing up, while the third method might be most efficient in that it exploits the available information best, depending on the research question, the method using ranks could nonetheless be better in providing the information of interest, such as when the focus lies on preferences for equal distributions. Despite the obvious shortcomings on theoretical grounds, the first method has its advantages too. Next to it being the most straightforward approach, it also allows us to make statements about the amount of money a change from one state to another in the experimental setup is "worth" directly. This was not done here, as the z-standardized scores were used to account for the fact that the amount that was distributed by the respondents varied randomly for four sums. 
However it is easy to imagine situations, in which such statements would be very useful, e.g. from a policy perspective, when evaluating the willingness-to pay for some kind of service.

Also, as we can see comparing tables 4 and 6, the R-squared goes down even though further variables have been added to the models. This is due to the fact that the variables operationalising need \& merit were included in their subsumed form instead of as single variables.

In regard to our hypotheses, we can reject the assumption of equal splits among friends as the norm. Both need as well as merit considerations were important for the distributions. This is not to say that equality might not be much more important in a situation between friends compared to e.g., the work setting. In regard to class differentials, we have somewhat mixed results. However, going by the results from the third method, we can say there is a tendency towards attaching more importance to merit in higher classes. However, this needs further inspection in future research.

\section{Conclusions}

In face of the multifaceted but fragmented literature on distributive justice, the goal of this paper was threefold. First, to introduce the distributional choice experiment (DSE) as a new method which was developed as a means of collecting information on distributive justice attitudes in an as efficient, comprehensive and direct manner as possible. The DSE is a new form of survey experiment that combines some of the favourable properties of choice and factorial survey experiments, also called vignette experiments, and also of distributional experiments otherwise conducted in the laboratory. While the DSE has the design of a choice experiment, to make sure the dimensions of the single vignettes that are shown together in a set, are uncorrelated, we have metric outcomes for each vignette, as in a factorial survey experiment. Additionally, instead of the logic of making justice evaluations indirectly by e.g., assessing the fairness of earnings in a factorial survey, in 
the DSE, the nature of the question at hand is more appropriately accounted for in the design. It allows the respondents to express their justice attitudes in a more direct manner, by actively distributing amounts among subjects. Given the very nature of the problem of allocating scarce goods, the fact that respondents had to explicitly distribute a given sum among three people forced them to go through the kind of cognitive process associated with such a task. It was necessary for the respondents to mentally assess the trade-offs between the conflicting principles of justice. Additionally, the DSE allows us to differentiate between individual effects and effects of the context and situation. As such, the DSE has a combination of several very desirable qualities, formerly lacking in any one method available for the assessment of attitudes towards distributive justice.

Second, since the DSE is a new method, a further goal and the focus of the paper was to introduce three possible analytical strategies. A first method is to treat the data from the DSE as if the outcomes were derived from a factorial survey experiment. While this is a nice way to achieve a first overview of the findings, an evident drawback is that the method does not take the interdependency of the outcome of a vignette in a DSE with the outcomes of the other two vignettes into account. The other two methods incorporate this interdependence by design. The second method does this by ranking the outcomes and the third by converting the outcomes into shares. Including this interdependency is a desirable property because of the inherent dependency of outcomes in allocations problems. The three methods were illustrated using data from the JInCS project. From a theoretical as well as efficiency perspective, the third method, which treats the outcomes of the single vignettes as shares of a whole, is perhaps the most useful method for most purposes. However, depending on the research question, the second method, using ranks, can provide information that the third method doesn't, such as on the propensity to distribute equally. The first method is especially useful to the researcher wanting a quick overview of the data, since it is not necessary to modify the outcome variable. Furthermore, the metric of the results can be useful to researchers 
interested in expressing the importance of the single variables in terms of money.

The third goal of the paper was to make a systematic contribution to the literature on distributive justice. The DSE that was used here asked respondents how they would distribute a specific sum among three people described in vignettes, if they were their friends. This situation was chosen in opposition to the job setting, typically used in distributive justice research (Jasso 1978; Auspurg, Hinz, and Sauer 2017). The data used here stems from a general population sample in Switzerland, as a counterbalance to the wide use of student samples. Unsurprisingly, the findings in regard to distributive justice differ slightly depending on the method used. In the models including just the variables from the DSE, the biggest difference concerns the differential treatment of the hypothetical friends depending on their ethnic origin, to the disadvantage of ethnic minorities. The results for the need and merit indicators are consistent in the expected direction throughout. Single friends and those who have 2 children received more money than those who live with a partner and do not have any children. Similarly, those who are in poor health and have a tight financial situation receive more than those in good health and those with a more relaxed financial situation. Next to these need considerations, merit also matters to the respondents. The hypothetical friends who were described as highly reliable and trustworthy received larger sums than those with the less desirable descriptions of lower reliability and trustworthiness. The respondents also gave more to the hypothetical friends they had known for a longer time. All of this speaks against the pure equality assumption in the situation of an allocative task among friends. In the models including both experiment and respondent level variables, we again see fairly consistent results through the three methodological approaches. The results are also comparable to the one-level models. When it comes to the hypothesized interaction between class and merit, for which higher classes were assumed to attach a higher value to merit, we can see hints in the expected direction. This is in line with the selfishness motive, according to which people favour those outcomes from which they 
would derive the highest benefits. The finding is also in line with cognitive dissonance reduction, according to which the better off need to justify their position, by telling themselves that it is only fair that they have attained what they have, e.g. through "hard work". However, as mentioned, since this result is not consistent throughout the different methods used, additional testing is certainly necessary.

On the whole, the paper offers insight into what people think is fair in a situation involving friends. More importantly however, the contribution illustrates the potential of the DSE and provides us with a powerful tool for further research. It invites us to delve deeper into the substance than was previously possible, by enabling us to differentiate between the effects of respondent characteristics, context and also the situation in which we face a problem of distributive justice. Especially in regard to context and situation, the cost-efficient and effective data collection inherent in the DSE offers us valuable opportunities to broaden our understanding of distributive justice. 


\section{Notes}

${ }^{1}$ At the time point of the draw, the institute had over 3 million entries. In a population of 8.4 million (2017), this corresponds to over a third of the Swiss population.

${ }^{2}$ In Switzerland, this is considered a very high response rate for a random sample form the general population

${ }^{3}$ Since the single variables are independent of each other per design, it is not possible to test the reliability of this scale

${ }^{4}$ The instructions additionally included a note stating that the three friends would be asked to keep the amount of the received sum a secret, so as not to cause envy amongst each other.

${ }^{5}$ The Hausman specification test can be used to compare the fixed effects estimator, which yields consistent coefficients, with the random effects estimator, which is consistent as well if there are no significant differences between the two estimators (Hausman 1978; Rabe-Hesketh and Skrondal 2012)

${ }^{6}$ The user written command xthybrid yields the same results without having to demean the variables first (Schunck and Perales 2017)

${ }^{7}$ Value 3 is assigned to the person who got the highest sum, value 1 to the person with the lowest sum and ties were treated as both or all belonging to the same rank with the next highest value.

${ }^{8}$ Of course if information on the equality principle is our chief interest, we can make it the dependent variable. 


\section{References}

Alexander, Cheryl S. and Henry Jay Becker (1978). "The Use of Vignettes in Survey Research". In: Public Opinion Quarterly 42.1, pp. 93-104. ISSN: 0033362X. DOI: 10. $1086 / 268432$.

Allison, Paul David (2009). Fixed effects regression models. Quantitative applications in the social sciences 160. Los Angeles: SAGE. 123 pp. ISBN: 978-0-7619-2497-5.

Allport, Gordon W. (1979). The nature of prejudice. Unabridged, 25th anniversary ed. Reading, MA: Addison-Wesley Pub. Co. 537 pp. ISBN: 978-0-201-00178-5 978-0-20100179-2.

Alves, Wayne M. and Peter H. Rossi (1978). "Who should get what? Fairness judgments of the distribution of earnings". In: American Journal of Sociology, pp. 541-564.

Angrist, Joshua David and Jörn-Steffen Pischke (2009). Mostly harmless econometrics: an empiricist's companion. Princeton: Princeton University Press. 373 pp. ISBN: 9780-691-12034-8 978-0-691-12035-5.

Arts, Wil and John Gelissen (2001). "Welfare States, Solidarity and Justice Principles: Does the Type Really Matter?" In: Acta Sociologica 44, pp. 283-299.

Auspurg, Katrin and Thomas Hinz (2015a). Factorial Survey Experiments. 2455 Teller Road, Thousand Oaks California 91320 United States: SAGE Publications, Inc. ISBN: 978-1-4522-7418-8 978-1-4833-9807-5. DOI: 10.4135/9781483398075.

- (2015b). "Multifactorial Experiments in Surveys". In: Experimente in den Sozialwissenschaften. Ed. by Marc Keuschnigg and Tobias Wolbring. 1st ed. Soziale Welt Sonderband 22. Baden-Baden: Nomos, pp. 291-315. ISBN: 978-3-8487-1916-7 978-3-84526043-3.

Auspurg, Katrin, Thomas Hinz, and Carsten Sauer (2015). "The factorial Survey as a Method for Measuring Sensitive Issues". In: EAM book series. New York: Routledge. 
- (Feb. 2017). "Why Should Women Get Less? Evidence on the Gender Pay Gap from Multifactorial Survey Experiments". In: American Sociological Review 82.1, pp. 179210. ISSN: 0003-1224, 1939-8271. DOI: 10.1177/0003122416683393.

Badgett, Lee and Nancy Folbre (2003). "Job gendering: Occupational choice and the marriage market". In: Industrial Relations: A Journal of Economy and Society 42.2, pp. 270-298.

Beck, Nathaniel and Jonathan N. Katz (1996). "Nuisance vs. Substance: Specifying and Estimating Time-Series-Cross-Section Models". In: Political Analysis 6, pp. 1-36. ISSN: 1047-1987, 1476-4989. DOI: 10.1093/pan/6.1.1.

Becker, Rolf and Christoph Zangger (2015). "Experimentelle Bildungsforschung". In: Experimente in den Sozialwissenschaften. Soziale Welt Sonderband 22. Baden-Baden: Nomos, pp. 105-131. ISBN: ISBN 978-3-8452-6043-3.

Boeri, Tito et al. (Apr. 1, 2001). "Would You like to Shrink the Welfare State? A Survey of European Citizens". In: Economic Policy 16.32, pp. 9-50. ISSN: 02664658. DOI: 10. $2307 / 3601033$.

Boulding, Kenneth E. (Mar. 1988). "Social justice as a Holy Grail: The endless quest". In: Social Justice Research 2.1, pp. 49-60. ISSN: 0885-7466, 1573-6725. DOI: 10.1007/ BF01052299.

Braybrooke, David (1987). Meeting needs. Studies in moral, political, and legal philosophy. Princeton, N.J: Princeton University Press. 344 pp. ISBN: 978-0-691-07727-7 978-0-691-02259-8.

Cohen, G. A. (1995). Self-ownership, freedom, and equality. Cambridge ; New York : [Paris, France]: Cambridge University Press ; Maison des sciences de l'homme. 277 pp. ISBN: 978-0-521-47174-9 978-0-521-47751-2 978-2-7351-0694-3 978-2-7351-0695-0.

Cohen, Ronald L (1986). Justice: Views from the Social Sciences. OCLC: 913697859. ISBN: 978-1-4899-3511-3 978-1-4899-3513-7. 
d'Anjou, Leo, Abram Steijn, and Dries Van Aarsen (1995). "Social position, ideology, and distributive justice". In: Social Justice Research 8.4, pp. 351-384.

Deutsch, Morton (July 1975). "Equity, Equality, and Need: What Determines Which Value Will Be Used as the Basis of Distributive Justice?" In: Journal of Social Issues 31.3, pp. 137-149. ISSN: 00224537, 15404560. DOI: $10.1111 /$ j . 1540-4560 . 1975 . tb01000.x.

Dillman, Don A. (2007). Mail and internet surveys: the tailored design method. 2nd ed., 2007 update with new internet, visual, and mixed-mode guide. Hoboken, N.J: Wiley. 523 pp. ISBN: 978-0-470-03856-7.

Dworkin, Ronald (2002). Sovereign virtue: the theory and practice of equality. 4. print. OCLC: 248761763. Cambridge, Mass.: Harvard Univ. Press. 511 pp. IsBn: 978-0-67400810-6 978-0-674-00219-7.

Eek, Daniel (1999). "Distributive Justice and Cooperation in Real-Life Social Dilemmas". PhD thesis. Göteborg, Sweden.

Erikson, Robert and John H. Goldthorpe (1992). The Constant Flux: A Study of Class Mobility in Industrial Societies. Oxford: Clarendon Press.

Faricy, Christopher and Christopher Ellis (Mar. 2014). "Public Attitudes Toward Social Spending in the United States: The Differences Between Direct Spending and Tax Expenditures". In: Political Behavior 36.1, pp. 53-76. ISSN: 0190-9320, 1573-6687. DOI: $10.1007 / \mathrm{s} 11109-013-9225-5$.

Festinger, Leon (1957). A Theory of Cognitive Dissonance. California: Stanford University Press.

Firebaugh, Glenn, Cody Warner, and Michael Massoglia (2013). "Fixed Effects, Random Effects, and Hybrid Models for Causal Analysis". In: Handbook of Causal Analysis for Social Research. Ed. by Stephen L. Morgan. Dordrecht: Springer Netherlands, pp. 113132. ISBN: 978-94-007-6093-6 978-94-007-6094-3. DOI: 10 . 1007/978-94-007-60943 3.7. 
Fiske, Alan Page (1992). "The Four Elementary Forms of Sociality: Framework for a Unified Theory of Social Relations". In: Psychological Review 99.4, pp. 689-723. ISSN: 0033-295X.

Franzese, Robert J. and Jude C. Hays (Apr. 2008). "Interdependence in Comparative Politics: Substance, Theory, Empirics, Substance". In: Comparative Political Studies 41.4, pp. 742-780. ISSN: 0010-4140, 1552-3829. DOI: 10.1177/0010414007313122.

Frohlich, Norman, Joe A. Oppenheimer, and Cheryl L. Eavey (Aug. 1987a). "Choices of Principles of Distributive Justice in Experimental Groups". In: American Journal of Political Science 31.3, p. 606. ISSN: 00925853. DOI: 10.2307/2111285.

- (Jan. 1987b). "Laboratory Results on Rawls's Distributive Justice". In: British Journal of Political Science 17.1, pp. 1-21. ISSN: 0007-1234, 1469-2112. DOI: 10.1017 / S0007123400004580.

FSO, Federal Statistical Office (2020). Household income and expenditure. Library Catalog: www.bfs.admin.ch. URL: https://www .bfs.admin.ch/bfs/en/home/statistiken/ wirtschaftliche-soziale-situation-bevoelkerung/einkommen-verbrauch-vermoegen/ haushaltsbudget.html (visited on 03/09/2020).

Glick, William H. and Karlene H. Roberts (Oct. 1984). "Hypothesized Interdependence, Assumed Independence". In: The Academy of Management Review 9.4, p. 722. ISSN: 03637425. DOI: $10.2307 / 258494$.

Greenberg, Jerald and Ronald L. Cohen, eds. (1982). Equity and justice in social behavior. New York: Academic Press. 492 pp. ISBN: 978-0-12-299580-4.

Hausman, J. A. (Nov. 1978). "Specification Tests in Econometrics". In: Econometrica 46.6, p. 1251. ISSN: 00129682. DOI: $10.2307 / 1913827$.

Henrich, Joseph (Sept. 2000). "Does Culture Matter in Economic Behavior? Ultimatum Game Bargaining Among the Machiguenga of the Peruvian Amazon". In: American Economic Review 90.4, pp. 973-979. ISSN: 0002-8282. DOI: 10.1257/aer.90.4.973. 
Henrich, Joseph Patrick, Ernst Fehr, and Herbert Gintis, eds. (2004). Foundations of human sociality: economic experiments and ethnographic evidence from fifteen smallscale societies. Oxford New York: Oxford University Press. 451 pp. ISBN: 978-0-19926204-5.

Hochschild, Jennifer L. (1981). What's fair? American beliefs about distributive justice. Cambridge, Mass: Harvard University Press. 345 pp. ISBN: 978-0-674-95086-3.

Homans, George Caspar (1974). Social behavior: its elementary forms. Rev. ed. New York: Harcourt, Brace, Jovanovich. 386 pp. ISBN: 978-0-15-581417-2.

Jasso, Guillermina (1978). "On the justice of earnings: A new specification of the justice evaluation function". In: American Journal of Sociology, pp. 1398-1419.

Kluegel, James R., David S. Mason, and Bernd Wegener, eds. (1995). Social justice and political change: public opinion in capitalist and post-communist states. Societies in transition 3. OCLC: 845018919. Berlin: de Gruyter. 359 pp. ISBN: 978-3-11-014541-0.

Konow, James (2001). "Fair and square: the four sides of distributive justice". In: Journal of Economic Behavior \&3 Organization 46.2, pp. 137-164.

Lamont, Julian and Christi Favor (2017). "Distributive Justice". In: The Stanford Encyclopedia of Philosophy. Ed. by Edward N. Zalta. Winter 2017. Metaphysics Research Lab, Stanford University.

Lerner, Melvin J. (Mar. 1977). "The justice motive: Some hypotheses as to its origins and forms1". In: Journal of Personality 45.1, pp. 1-52. ISSN: 0022-3506, 1467-6494. DOI: 10.1111/j.1467-6494.1977.tb00591.x.

Lerner, Melvin J. and Sally C. Lerner (1981). The Justice Motive in Social Behavior: Adapting to Times of Scarcity and Change. OCLC: 913697948. ISBN: 978-1-4899-04294 978-1-4899-0431-7.

Leventhal, Gerald S. (1976). "Fairness in Social Relationships". In: Contemporary topics in social psychology. Ed. by John W. Thibaut et al. Morristown, N.J: General Learning Press, pp. 211-240. ISBN: 978-0-382-25078-1. 
Leventhal, Gerald S., Arthur L. Popp, and Llewlee Sawyer (Dec. 1973). "Equity or Equality in Children's Allocation of Reward to Other Persons?" In: Child Development 44.4, p. 753 . ISSN: 00093920. DOI: $10.2307 / 1127720$.

Lewin-Epstein, Noah, Amit Kaplan, and Asaf Levanon (2003). "Distributive justice and attitudes toward the welfare state". In: Social Justice Research 16.1, pp. 1-27.

Li, Meng and David P. Tracer, eds. (2017). Interdisciplinary Perspectives on Fairness, Equity, and Justice. Cham: Springer International Publishing. ISBN: 978-3-319-58992-3 978-3-319-58993-0. DOI: 10.1007/978-3-319-58993-0.

Liebig, Stefan et al. (2015). "How Much Inequality of Earnings Do People Perceive as Just? The Effect of Interviewer Presence and Monetary Incentives on Inequality Preferences". In: methods, data, analyses 9.1.

Louviere, Jordan J., Terry N. Flynn, and Richard T. Carson (2010). "Discrete Choice Experiments Are Not Conjoint Analysis". In: Journal of Choice Modelling 3.3, pp. 5772. ISSN: 17555345 . DOI: $10.1016 / \mathrm{S} 1755-5345(13) 70014-9$.

Miller, David (2003). Principles of social justice. 3. print. Cambridge, Mass.: Harvard Univ. Press. 337 pp. ISBN: 978-0-674-00714-7 978-0-674-70628-6.

Mueller, Eva (May 1963). "Public Attitudes Toward Fiscal Programs". In: The Quarterly Journal of Economics 77.2, p. 210. ISSN: 00335533. DOI: $10.2307 / 1884400$.

Nielsen, Kai (1979). "Radical egalitarian justice: justice as equality". In: Social Theory and Practice 5.2, pp. 209-226.

Nozick, Robert (2013). Anarchy, state, and utopia. New York: Basic Books, a member of the Perseus Books Group. 372 pp. ISBN: 978-0-465-05100-7.

Piketty, T. (Aug. 1, 1995). "Social Mobility and Redistributive Politics". In: The Quarterly Journal of Economics 110.3, pp. 551-584. ISSN: 0033-5533, 1531-4650. DOI: 10.2307/ 2946692. 
Rabe-Hesketh, S. and Anders Skrondal (2012). Multilevel and longitudinal modeling using Stata. 3rd ed. OCLC: ocn787853271. College Station, Tex: Stata Press Publication. 2 pp. ISBN: 978-1-59718-108-2 978-1-59718-103-7 978-1-59718-104-4.

Rabin, Matthew (1995). "Moral Preferences, Moral Constraints, and Self-Serving Biases y". In: Berkeley Department of Economics Working Paper (No. 95-241), p. 34.

Rawls, John (2005). A theory of justice. Orig. ed., reprint. OCLC: 611053537. Cambridge, Mass.: Belknap Press. 607 pp. ISBN: 978-0-674-01772-6.

Robinson, Robert V. and Wendell Bell (Apr. 1, 1978). "Equality, Success, and Social Justice in England and the United States". In: American Sociological Review 43.2, pp. 125-143. ISSN: 00031224. DOI: $10.2307 / 2094695$.

Rossi, Peter H. and Andy B. Anderson (1982). "The Factorial Survey Approach: An Introduction". In: Measuring Social Judgements. Ed. by Peter H. Rossi and Steven L. Nock. Beverly Hills: Sage Publications. ISBN: 0-8039-1816-X.

Rossi, Peter H. and Steven L. Nock, eds. (1982). Measuring social judgments: the factorial survey approach. Beverly Hills: Sage Publications. 255 pp. ISBN: 978-0-8039-1816-0.

Sampson, Edward E. (July 1975). "On Justice as Equality". In: Journal of Social Issues 31.3, pp. 45-64. ISSN: 00224537, 15404560. DOI: 10.1111/j.1540-4560.1975. tb00996.x.

Samuelson, William and Richard Zeckhauser (Mar. 1988). "Status quo bias in decision making". In: Journal of Risk and Uncertainty 1.1, pp. 7-59. ISSN: 0895-5646, 1573-0476. DOI: $10.1007 / \mathrm{BF} 00055564$.

Sauer, Carsten et al. (2009). "A Factorial Survey on the Justice of Earnings within the SOEP-Pretest 2008". In:

Schunck, Reinhard (Mar. 2013). "Within and between Estimates in Random-Effects Models: Advantages and Drawbacks of Correlated Random Effects and Hybrid Models". In: The Stata Journal: Promoting communications on statistics and Stata 13.1, pp. 65-76. ISSN: 1536-867X, 1536-8734. DOI: 10.1177/1536867X1301300105. 
Schunck, Reinhard and Francisco Perales (2017). "Within- and between-cluster effects in generalized linear mixed models: A discussion of approaches and the xthybrid command". In: Stata Journal 17.1. Place: College Station, TX Publisher: Stata Press, pp. 89-115.

Scott, John T. and Brian H. Bornstein (July 2009). "What's Fair in Foul Weather and Fair? Distributive Justice across Different Allocation Contexts and Goods". In: The Journal of Politics 71.3, pp. 831-846. ISSN: 0022-3816, 1468-2508. DOI: 10.1017 / S0022381609090744.

Sen, Amartya Kumar (2009). The idea of justice. London: Allen Lane. 467 pp. ISBN: 978-1-84614-147-8.

Shepelak, Norma J. (1989). "Ideological stratification: American beliefs about economic justice". In: Social Justice Research 3.3, pp. 217-231.

Smith, Adam (1976). An inquiry into the nature and causes of the wealth of nations. Chicago: University of Chicago Press. 524 pp. ISBN: 978-0-226-76374-3.

Street, Deborah J., Leonie Burgess, and Jordan J. Louviere (Dec. 2005). "Quick and easy choice sets: Constructing optimal and nearly optimal stated choice experiments". In: International Journal of Research in Marketing 22.4, pp. 459-470. ISSN: 01678116. DOI: $10.1016 / j$. ijresmar.2005.09.003.

Wallander, Lisa (Sept. 2009). "25 years of factorial surveys in sociology: A review". In: Social Science Research 38.3, pp. 505-520. ISSN: 0049089X. DOI: 10.1016/j .ssresearch . 2009.03 .004 .

Walster, Elaine, Ellen Berscheid, and G. William Walster (1973). "New directions in equity research." In: Journal of personality and social psychology 25.2, p. 151.

Yaari, M. E. and M. Bar-Hillel (May 1984). "On dividing justly". In: Social Choice and Welfare 1.1, pp. 1-24. ISSN: 0176-1714, 1432-217X. DOI: 10.1007/BF00297056. 
Zangger, Christoph (Nov. 17, 2019). "Making a place for space: Using spatial econometrics to model neighborhood effects". In: Journal of Urban Affairs 41.8, pp. 1055-1080. ISSN: 0735-2166, 1467-9906. DOI: $10.1080 / 07352166.2019 .1584530$. 